\title{
Editorial do dossiê "Reformas da investigação preliminar e a investigação defensiva no processo penal" - Investigação preliminar: desafios e perspectivas
}

\begin{abstract}
Editorial of dossier "Reforms in criminal investigation and defensive investigation in criminal procedure" Preliminary investigation: challenges and perspectives
\end{abstract}

\author{
Marta Saad ${ }^{1}$ \\ Universidade de São Paulo - São Paulo/SP, Brasil \\ martasaad@usp.br \\ http://lattes.cnpq.br/3199855414351538 \\ Dhttps://orcid.org/0000-0001-5363-390X
}

\begin{abstract}
Resumo: Este editorial analisa as funções e finalidades da investigação preliminar e os atos que são praticados nessa fase, provisórios ou definitivos. Cuida da influência desta etapa na ação penal e do exercício do direito de defesa, assim como da investigação defensiva. O editorial dialoga com os autores do dossiê, apresentando os textos.

Palavras-chave: Editorial; investigação preliminar; inquérito policial; direito de defesa; investigação defensiva; investigação interna.
\end{abstract}

AвstRAct: The editorial addresses the functions and purposes of the preliminary investigation and the various associated acts, provisional or definitive. It covers the influence of preliminary investigation over criminal prosecution and the exercise of defense in police inquiries as well as through

1 Doutora e Mestre em Direito Processual Penal pela USP. Professora Doutora do Departamento de Direito Processual da Faculdade de Direito da Universidade de São Paulo. Foi Presidente do IBCCRIM (Instituto Brasileiro de Ciências Criminais) e Assessora de Ministro do Supremo Tribunal Federal. Presidente da REDE Ibero-Americana de Advocacia Criminal. Advogada. 
investigations by the defense. The editorial dialogues with the authors of the dossier, introducing the texts.

KEYWORDS: Editorial; preliminary investigation; police inquiry; right of defense; defensive investigation; internal investigation.

\section{INTRODUÇÃo}

A fase de investigação preliminar foi durante muito tempo esquecida pela doutrina. Poucos eram os trabalhos que se voltavam a analisar a primeira fase da persecução penal, sua importância, dificuldades e desafios. Isso, claro, repercutia na própria prática da atividade, negligenciada e pouco prestigiada.

Nos últimos anos, os dois extremos da persecução penal - a investigação preliminar e a execução penal - têm paulatinamente recebido a importância que lhes é devida. Este dossiê, intitulado "Investigação preliminar: desafios e perspectivas”, vem, portanto, em boa hora.

O motivo para funcionar como coordenadora deste dossiê temático certamente repousa na generosidade da Equipe Editorial da Revista Brasileira de Direito Processual, ao reconhecer algum valor no trabalho relacionado ao assunto que escrevi há mais de quinze anos.

Desde que comecei meus estudos acadêmicos, minha pesquisa se voltou para a primeira fase da persecução penal, notadamente o inquérito policial. Como fruto do meu trabalho de mestrado, publiquei, em 2004, O direito de defesa no inquérito policial. ${ }^{2}$ Estavam ali ideias que me inquietavam na prática do sistema de justiça criminal, que via no inquérito policial uma etapa de menor importância e, em consequência, mantinha o investigado alheio ao desenrolar da persecução penal.

Muito se caminhou desde então e ver este dossiê temático publicado, com tantas ideias interessantes expostas e exploradas, foi um presente especial, pelo qual publicamente agradeço.

2 SAAD, Marta, O direito de defesa no inquérito policial. São Paulo: RT, 2004. 
Aproveito a oportunidade para parabenizar o trabalho primoroso da Equipe Editorial da Revista e, claro, dos autores dos artigos ora publicados, que contribuem com importantes reflexões sobre o tema. Proponho abaixo um diálogo com esses textos, que compõem de maneira orgânica o temário deste dossiê.

\section{Funções E FINALIDADES DA INVESTIGAÇão PRELIMINAR}

A investigação preliminar, visando a apurar o fato, que aparenta ser ilícito e típico, bem como sua autoria, coautoria e participação, é procedimento prévio, cautelar, realizado no mais das vezes pela polícia judiciária, em inquérito policial, procedimento de natureza administrativa e finalidade judiciária.

Desde a legislação processual de 1871, quando se atribuiu aos delegados de polícia, nos distritos, a incumbência de se proceder imediatamente à coleta de elementos para apuração da infração penal até a chegada dos juízes de direito, competentes para a formação da culpa, reconheceu-se a necessidade de se adotar determinadas medidas de urgência, a fim de que os vestígios da infração não desaparecessem ou se perdessem no tempo.

O inquérito policial reveste-se, assim, de natureza cautelar, no sentido de preservação de eventuais elementos ou meios de prova. A cautelaridade não se confunde, todavia, com eventual provisoriedade que alguns elementos, constantes no inquérito policial, possam ostentar. Há determinados atos do inquérito que se transmitem para o bojo de futura ação penal de forma definitiva, posto que impossíveis de repetição ou renovação, tais como os exames, vistorias e avaliações, a busca e a apreensão, bem ou mal sucedida, o arresto, o sequestro de bens.

Assim, sem perder a natureza cautelar, de preservação do meio de prova, procedendo-se com urgência diante da dificuldade de se obter determinados elementos com o passar do tempo, a cautelaridade ínsita aos atos do inquérito não se confunde com provisoriedade, visto que muitos dos atos acabam transcendendo essa possível característica, convertendose de provisórios em permanentes.

Ao lado do atendimento à urgência, a investigação preliminar também surge cautelar no sentido de evitar excessos que a imediatidade 
de eventual ação penal poderia trazer à honra e à reputação do envolvido no processo penal.

A função do inquérito policial consiste, portanto, em colher elementos tão logo chegue à autoridade policial a notícia da infração, os quais poderiam desaparecer pela ação do tempo.

A investigação preliminar, além disso, ostenta ainda finalidades de duas ordens. A primeira delas é a de reconstruir o fato investigado, informando e instruindo a autoridade judicial e o acusador, público ou privado. O inquérito policial não é só base para a acusação, mas também para o arquivamento, quando se constata que os elementos de informação lá constantes são falhos quanto ao fato e/ou à autoria, ou porque demonstram que o fato apurado é inexistente ou atípico, ou, ainda, comprovam a existência de causa de exclusão da antijuridicidade ou causa de extinção da punibilidade. Por isso, deve-se também produzir provas em favor do suspeito ou do indiciado.

A segunda finalidade do inquérito é a de ministrar elementos para que o juiz possa se convencer acerca da necessidade ou não se de decretar a prisão preventiva, o arresto e sequestro de bens, a busca e a apreensão, a quebra do sigilo bancário ou telefônico. Serve, portanto, de base para decretação de medidas e provimentos cautelares, no curso do inquérito.

\section{O QUE SE PRODUZ NA INVESTIGAÇÃo PRELIMINAR: ATOS PROPRIAMENTE DE INVESTIGAÇÃO E ATOS DE INSTRUÇÃO}

É certo, ainda, que a investigação preliminar abriga não só atos de investigação, mas também atos de instrução criminal, alguns de caráter transitório e outros de caráter definitivo.

Com efeito, a partir da instauração da investigação, inúmeros atos que acarretam restrição a direitos constitucionalmente assegurados podem ser tomados em desfavor do investigado, tais como os decretos de prisão preventiva e temporária, se o inquérito já não tiver se iniciado por meio de flagrante, em nítida restrição ao direito de liberdade.

Pode ainda ter lugar, no curso da investigação preliminar, a decretação de medidas cautelares, como a busca pessoal ou domiciliar, que limita os direitos de inviolabilidade do domicílio, da intimidade e 
da vida privada e a integridade física e moral do indivíduo; a apreensão, que pode restringir o direito a liberdade, tutela e curatela, a posse e a propriedade; a decretação do arresto ou sequestro de bens, que limitam a fruição da posse e propriedade; a quebra dos sigilos fiscal e bancário, que atinge a intimidade e a vida privada; a interceptação das comunicações telefônicas, que restringe o sigilo das comunicações; a determinação do indiciamento, que acarreta abalo moral, familiar e econômico; e, pior, ao fim, possível formalização da acusação, com o início da segunda fase da persecução penal, por meio da decisão de recebimento da denúncia, ou queixa.

A respeito das atividades investigativas desenvolvidas na primeira fase, e dos métodos possivelmente empregados, o artigo intitulado "Considerações sobre a confissão e o método Reid aplicado na investigação criminal”, de Lívia Yuen Ngan Moscatelli, trata de técnicas de investigação. Analisa sua compatibilidade com as garantias processuais asseguradas ao interrogado e com uma investigação epistemicamente qualificada, afastando método de interrogatório que vise a incitar a confissão do suspeito com a utilização do blefe e da manipulação psicológica.

Ainda sobre o que se produz em investigação preliminar, alguns trabalhos deste dossiê tratam da prova técnica ou científica.

Álice Lira Cardos, Gabriella Medeiros Silva, Thiago Pinto Siqueira Campos, Lizanda Monteiro Ciraulo e Carmen Walentina Amorim Gaudêncio Bezerra, no artigo "Avaliação psicológica de agressores no contexto brasileiro: instrumentos e perspectivas”, mostram que a avaliação clínica forense, destinada à avaliação de personalidade, risco de violência e reincidência criminal, agressividade, entre outros, carece de escassez científica e metodológica na prática nacional, no tocante à avaliação dos agressores sexuais.

Em "Achieving defense by means of forensic science during the criminal proceedings in Romania", Delia Magherescu mostra que a necessidade de se olhar para a importância da prova técnica nesta fase do procedimento criminal não é um problema exclusivo do Brasil. Há importância da atividade defensiva por meio de ciências forenses, de forma a contribuir legal e substancialmente para a solução de casos. $\mathrm{O}$ trabalho propõe não só a ideia de exercício do direito de defesa na fase de investigação, como também as conexões possíveis entre esta atividade 
e os meios de prova científica, notadamente nos casos de crimes contra a vida, corrupção, falsidade documental, terrorismo.

Ainda, Francisco Assis de França Júnior, Bruno Cavalcante Leitão Santos e Felipe Costa Laurindo do Nascimento, em "Aspectos críticos da expansão das possibilidades de recursos tecnológicos na investigação criminal: a inteligência artificial no âmbito do sistema de controle e de punição", cuidam das potenciais influências negativas da utilização de novas tecnologias na investigação, sob o ponto de vista dos direitos de intimidade e vida privada.

Em outro giro, outros dois artigos deste dossiê tratam da influência dos elementos obtidos no inquérito policial na sentença penal.

A rigor, os elementos produzidos em inquérito policial destinam-se a convencer quanto à viabilidade ou não da ação penal ou quanto às condições necessárias para a decretação de qualquer medida ou provimento cautelar no curso da investigação. Com vistas a estas decisões, tomadas na etapa preliminar, os dados colhidos não só informam, mas convencem, tais como as declarações de vítimas, os depoimentos de testemunhas, as declarações dos acusados, a acareação, o reconhecimento, o conteúdo de determinados documentos juntados aos autos, as perícias em geral (exames, vistorias e avaliações), a identificação dactiloscópica, o estudo da vida pregressa, a reconstituição do crime.

Mas, excluindo-se as provas irrepetíveis, sua função deveria se esgotar nesta fase inaugural. Até mesmo por isso, com a reforma processual operada em 2008, o Código de Processo Penal passou a vedar a utilização de elementos de informação obtidos no inquérito para fundamentar, de maneira exclusiva, sentença penal.

O artigo de autoria de André Rocha Sampaio, Marcelo Herval Macedo Ribeiro e Amanda Assis Ferreira trata exatamente da burla desta previsão legal, analisando a influência dos elementos de informação do inquérito policial na fundamentação da sentença penal condenatória. Por intermédio de pesquisa empírica quantitativa-qualitativa, analisando processos casos julgados em 2016 em Maceió, Alagoas, objetivou-se verificar se o inquérito policial é utilizado na fundamentação de sentenças judiciais, chegando-se à conclusão, depois da coleta e análise de dados, de que na grande maioria dos casos analisados o magistrado utilizou expressamente algum elemento informativo produzido durante as investigações 
preliminares, sendo que, neste, quase a totalidade dos processos terminou em sentença condenatória.

Já no artigo intitulado "A imbricação entre maxiprocessos e colaboração premiada: o deslocamento do centro informativo para a fase investigatória, na Operação Lava-Jato", Antonio Eduardo Ramires Santoro defende, por meio de exemplos da casuística recente, que, nos chamados maxiprocessos, a informação sobre os fatos que forma o convencimento do julgador é produzida durante a fase investigatória, havendo assim o deslocamento do centro informativo definidor da sorte do processo da fase instrutória processual, que seria a adequada porque produzida perante o juiz em contraditório, para a investigação preliminar, por meio dos acordos de colaboração premiada.

Estes dois últimos artigos têm em comum o questionamento sobre o desvirtuamento do que se produz em investigação preliminar: uma etapa cautelar e urgente, que tem se inflado de forma a antecipar e esvaziar, em caso de haver ação penal, a instrução produzida em juízo.

\section{Da negaÇÃo dA POSSIBILIDAdE DE DEFESA NA INVESTIGAÇÃo PRELIMINAR À INVESTIGAÇÃO DEFENSIVA}

Justamente por ser a investigação preliminar etapa importante para a obtenção de elementos de informação, inclusive com atos que depois não mais se repetem, o investigado deve contar com assistência de defensor já nesta fase preliminar, preparando adequada e tempestivamente sua defesa, substancial, de conteúdo.

A possibilidade de exercício do direito defesa na primeira fase da persecução penal é algo relativamente recente na jurisprudência brasileira. Durante mais de cinquenta anos, conviveu-se com a crença infundada de que o inquérito policial não passava de peça administrativa, meramente informativa, que ostentava unicamente atos de investigação. Em consequência, negava-se ao indiciado - ou informalmente acusado - o exercício do direito de defesa nesta fase da persecução penal

Não obstante a prática jurídica assim se ostentasse, alguns progressos legislativos foram sendo efetuados em direção ao reconhecimento do direito de defesa na persecução penal prévia: o Estatuto da Ordem dos 
Advogados do Brasil prevê o direito de o advogado consultar os autos do inquérito e de entrevistar, reservadamente, o seu cliente. No Estado de São Paulo, a Portaria n. ${ }^{\circ}$ 18/1998, da Delegacia Geral de Polícia, trouxe importantes inovações no campo da publicidade do inquérito. E, mais que tudo, a Constituição da República, de 1988, relançou o debate, ao dispor, no artigo $5^{\circ}$, inciso LV, que aos acusados em geral são assegurados o contraditório e a ampla defesa. Ainda assim, a prática forense quase unânime insistia em manter o acusado alheio aos atos praticados no curso do inquérito.

Há pouco mais de dez anos, porém, passou-se por momento de inflexão na jurisprudência no que toca a este tema: depois de décadas, os Tribunais Superiores passaram a reconhecer a possibilidade de exercício do direito constitucional de defesa nesta fase, assegurando a vista dos autos de inquérito ao acusado e seu defensor, bem como a participação defensiva nesta fase. O entendimento acabou, inclusive, sufragado na edição de súmula vinculante neste sentido, a súmula vinculante $n .^{\circ} 14$.

Hoje, potencializando a publicidade interna e o acesso à integralidade dos atos, iniciativas como a do inquérito eletrônico podem possibilitar de maneira mais efetiva a atividade defensiva. Eliminado o registro em papel, o inquérito realizado de forma eletrônica permite ganhos de celeridade e controle, por todos os envolvidos.

Em “ $A$ introdução do juiz das garantias no Brasil e o inquérito policial eletrônico”, Sarah Gonçalves Ribeiro e Rodrigo Régnier Chemim Guimarães mostram que o inquérito eletrônico permite tanto ao Ministério Público quanto à defesa maior participação na investigação, dada a possibilidade de acompanhamento do trâmite da investigação, disponibilizada a todo tempo, o que amplia a eficiência, transparência, celeridade nos atos de comunicação e facilidade de acesso aos autos, aumentando o desempenho da atividade estatal. Vão, porém, além, mostrando que o inquérito eletrônico é inclusive parte da solução para a adaptação brasileira ao modelo do juiz das garantias.

Nicolás Omar Vargas, em "La producción de prueba de descargo por parte de la defensa en el processo penal em Argentina durante la etapa de instrucción o invetigación. Un análisis comparativo entre processos inquisitivos y acusatórios", lança luz sobre o estágio de discussão sobre o 
direito de defesa, sob o ponto de igualdade de armas, na primeira fase da persecução penal na Argentina, que convive com Códigos variados, de matizes diversos.

Se no Brasil durante muito tempo a participação defensiva em investigação oficial foi negada, hoje, superado tal óbice, enfrenta-se o desafio da efetiva implementação e regulamentação em lei federal da atividade de investigação defensiva, com vistas a assegurar a paridade de armas.

No artigo "A investigação criminal direta pela defesa - instrumento de qualificação do debate probatório na relação processual penal”, Franklyn Roger Alves Silva defende que a investigação criminal já não pode ser reduzida a inquérito policial, produzido pela polícia judiciária, tendo em conta que há hoje investigação direta pelo Ministério Público e investigações produzidas em procedimentos sancionatórios. Entende que a investigação defensiva é espécie então deste gênero mais amplo de investigação criminal, tanto por meio do inquérito defensivo - realizado em favor do imputado - como do inquérito auxiliar, em favor da vítima. A investigação defensiva permite ao acusado contribuir com esclarecimento dos fatos, identificar fontes de prova e até avaliar, de maneira mais qualificada, sua estratégia defensiva, inclusive qualificando-o para decidir sobre a opção de seguir por meios consensuais, como acordo de colaboração premiada. Depois de analisar experiência estrangeira - Estados Unidos e Itália - e algumas normas de ordenamento brasileiro que já permitem de maneira incipiente a investigação, propõe que sejam feitos outros ajustes mais significativos, principalmente no Código de Processo Penal e nas leis que regem a advocacia e Defensoria Pública, para consolidar a prática da investigação defensiva no Brasil.

O trabalho de Anna Carolina Canestraro e Túlio Felipe Xavier Januário, intitulado "Investigação defensiva corporativa: um estudo do Provimento n. 188/208 e de sua eventual aplicação paras as investigações internas", por fim, analisa justamente a aplicação do Provimento n. ${ }^{\circ}$ 188/2018 do Conselho Federal da Ordem dos Advogados do Brasil, que cuida da investigação defensiva, à chamada investigação defensiva corporativa, própria de compliance, verificando as diligências possíveis de ser desenvolvidas e a questão do sigilo. 
O presente dossiê caminha assim por artigos que analisam o que é produzido na fase de investigação preliminar, os reflexos indevidos do material colhido em investigação preliminar em eventual sentença proferida ao fim de ação penal e o incremento da atividade defensiva nesta etapa.

Os textos dialogam, mostram a mesma inquietação, e contribuem efetivamente para o debate sobre o tema e para a pesquisa, daí que convido a todos para a leitura deste importante dossiê temático.

\section{REFERÊNCIAS BIBLIOGRÁFICA}

ARAÚJO, Marcelo Azambuja. Considerações sobre o tratamento da investigação criminal defensiva no PLS n. 156/09. Revista justiça e sistema criminal: modernas tendências do sistema criminal, Curitiba, v. 9, n. 16, p. 233-246, 2017.

BALDAN, Édson Luís. Investigação defensiva: o direito de defender-se provando. Revista Brasileira de Ciências Criminais, São Paulo, v. 15, n. 64, p. 253-273, jan./ fev. 2007.

BALDAN, Édson Luís. Lineamentos da investigação criminal defensiva no Provimento 188/2018 do Conselho Federal da OAB. Boletim do Instituto Brasileiro de Ciências Criminais, ano 27, n. 322, pp. 7-9, set/2019.

BARROS, Flaviane de Barros. (Re)forma do processo penal: Comentários críticos dos artigos modificados pelas Leis n. 11.690/08 e n.11.900/09. $2^{\text {a }}$. ed. Belo Horizonte: Del Rey, 2009.

BRIAN, Brad D.; McNeil, Barry F.; DEMSKY, Lisa J. Internal corporate investigations. $4^{\text {th }}$ ed. Nova York: ABA Book Publishing, 2018.

DIAS, Gabriel Bulhões Nóbrega. Manual prático de investigação defensiva: um novo paradigma na advocacia criminal brasileira. Florianópolis: EMais, 2019.

FERNANDES, Antonio Scarance. Processo penal constitucional. 4. ed.. São Paulo: RT, 2005.

GIACOMOLLI, Nereu José. A fase preliminar do processo penal: crises, misérias e novas metodologias investigatórias. Rio de Janeiro: Lumen Juris, 2011.

LOPES JR., Aury. Direito processual penal. 16ª . ed. São Paulo: Saraiva, 2019. 
LOPES JR., Aury. GLOECKNER, Ricardo Jacobsen. Investigação preliminar no processo penal. 6a ${ }^{\mathrm{a}}$. ed.. São Paulo: Saraiva, 2014.

MACHADO, André Augusto Mendes. Investigação criminal defensiva. São Paulo: Revista dos Tribunais, 2010.

MALAN, Diogo Rudge. Defesa penal efetiva. Ciências Penais: Revista da Associação Brasileira de Professores de Ciências Penais, São Paulo, v. 3, n. 4, p. 253-277, jan./jun. 2006.

MALAN, Diogo Rudge. Investigação defensiva no processo penal. Revista Brasileira de Ciências Criminais, São Paulo, v. 20, n. 96, p. 279-309, maio/jun. 2012.

NARDELLI, Marcella Alves Mascarenhas; CUNHA NETO, Eurico da. A investigação defensiva como corolário da igualdade processual e do direito à prova. Revista jurídica UNIGRAN, Dourados, v. 17, n. 33, p. 133-148, 2015.

OLIVEIRA, Francisco da Costa. A defesa e a investigação do crime. 2. ed. Coimbra: Almedina, 2008.

PIMENTEL JUNIOR, Jaime; MORAES, Rafael Francisco Marcondes de. Polícia judiciária e a atuação da defesa na investigação criminal. 2. ed.. São Paulo: Juspodivm, 2018.

SAAD, Marta. O direito de defesa no inquérito policial. São Paulo: Revista dos Tribunais, 2004.

SAYEG, Ronaldo. O inquérito policial democrático. Rio de Janeiro: Lumen Juris, 2019.

VILARES, Fernanda Regina; BEDIN, Guilherme Augusto Campos; CASTRO, Pedro Machado de Almeida. Investigação criminal: o projeto de Código de Processo Penal e investigação defensiva. Revista Brasileira de Ciências Criminais, São Paulo, v. 22, n. 107, p. 309-336, mar./abr. 2014. 


\section{Informações adicionais e declarações do autor (integridade científica)}

Declaração de conflito de interesses (conflict of interest declaration): a autora confirma que não há conflitos de interesse na realização das pesquisas expostas e na redação deste editorial.

Declaração de autoria (declaration of authorship): todas e somente as pessoas que atendem os requisitos de autoria deste editorial estão listadas como autores.

Declaração de ineditismo e originalidade (declaration of originality): a autora assegura que o texto aqui publicado não foi divulgado anteriormente em outro meio e que futura republicação somente se realizará com a indicação expressa da referência desta publicação original; também atesta que não há plágio de terceiros ou autoplágio.

\section{COMO CITAR ESTE EDITORIAL:}

SAAD, Marta. Editorial do dossiê "Investigação preliminar: desafios e perspectivas". Revista Brasileira de Direito Processual Penal, Porto Alegre, vol. 6, n. 1, p. 29-40, jan./abr. 2020. https://doi.org/10.22197/rbdpp.v6i1.348

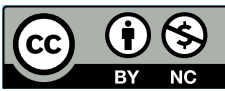

Esta obra está licenciada com uma Licença Creative Commons Atribuição-NãoComercial 4.0 Internacional. 